\title{
A Summary of Innovation and Reform of Economic Development Pattern in New Era
}

\author{
Weicheng Jiang ${ }^{1, a}$,Yezi $\mathrm{Yu}^{1, \mathrm{~b}}$,Ting Zhao ${ }^{1, \mathrm{c}}$,Changhai $\mathrm{Yao}^{1, \mathrm{~d}}$, \\ Kexin Tang ${ }^{1, e}$ and Junlan Liu $^{1, f}$ \\ ${ }^{1}$ JiShou university ZhangJiajie college, ZhangJiajie, 427000, Peoples R China

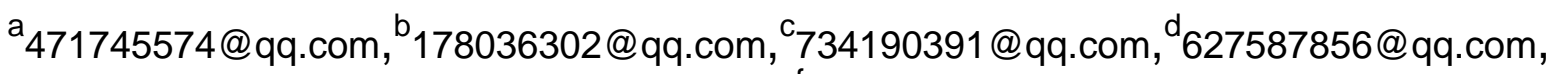 \\ e2365485651@qq.com, ${ }^{f} 1158117160 @ q q . c o m$
}

Keywords: New era; Economic development pattern; Innovation and transformation; Evaluation index; Summary

\begin{abstract}
The innovation and transformation of economic development pattern in the new era are the internal requirements of implementing scientific development and realizing sound and rapid economic development. The thesis reviews and summarizes the connotation, existing problems and difficulties, experiences and reference, evaluation system, thinking and timing of innovation and transformation of economic development pattern in the new era and points out the direction for further research.

Domestic research on transforming the economic development pattern started in the mid-1990s. In recent years, especially after the baptism of the financial crisis, the transformation of economic development has become a hot issue discussed by both theorists and practitioners in China. From the existing literature, domestic research mainly focuses on five aspects, including transforming the connotation of economic development pattern, problems and difficulties, experience, evaluating system, thinking and countermeasures. The thesis does a review of this, trying to find a breakthrough for further research.
\end{abstract}

\section{Transforming the Connotation of Economic Development Pattern}

Most scholars understand and define the connotation of changing the mode of economic development, from the perspective of distinguishing between the economic growth pattern and the economic development pattern. Huang Taiyan (2007) argues that the transformation of economic development means not only the transformation from extensive growth to intensive growth or from epitaxial growth to connotation growth, but also to the diversification of development objectives and the simultaneous transformation of the quality and efficiency of economic growth, to the people-oriented development, to the full-scale optimization of the economic structure, to the development mode under the condition of a knowledge-based economy, to the resource-saving and environment-friendly society. Liu Shijia (2007) pointed out that compared with the transforming of the economic growth pattern, transformation of the economic development pattern is more comprehensive and extensive, paying more attention to the structural change and the improvement of the "quality", paying more attention to the overall planning and balanced development. Liu Xiangrong (2009) argues that the economic development pattern is different the economic growth pattern. The latter is a simple economic concept emphasized more on the quantity, while the former is a concept which units the quantity and quality, involving the relationship between economy and society, economic society and population, resources and environment. There are three connotations in transforming the economic development pattern, or we should stick to three orientations, including scientific orientation, human orientation and ecological orientation. The three orientations are different from each other and indispensable, but also associated with each other to form an organic whole. Zhang Yunping (2009) argues that, compared with the economic growth pattern, the connotation of the economic development pattern is more abundant. At the present stage, the connotation of the transformation of the economic development pattern in our country includes at least the contents of raising the rate, optimizing the structure, harmonizing 
naturally, running steadily and coordinating and coordinating with each other. Qi Jianguo (2010) argues that under the scientific development concept, the key connotation of transforming the mode of economic development is to properly handle the material benefit distribution among people, handle the relationship between man and nature, and achieve the harmony of the material interests of the society and realize harmony between man and nature. However, the basis for the transformation of the economic development pattern is the transformation of the economic growth pattern. Shen Luying, et al (2010) believe that under the more complicated macroeconomic situation, under the more explicit national strategy, and under the more urgent goal of urban development, Shanghai has been given a new approach to transforming its economic development pattern as follows. Take the road of service economy and lay the industrial foundation for transforming the economic development pattern. Take the road of independent innovation and enhance the endogenous impetus of transforming the economic development pattern. Take the road of functional upgrading and focus on the key aspects of transforming the economic development pattern. Take the road of resource intensiveness and break through the bottleneck constraints in transforming the economic development pattern. Take the people-oriented road and implement the fundamental purpose of transforming the economic development pattern.

\section{Problems and Difficulties in Transforming the Economic Development Pattern}

Fang Zhuzheng (2009) believes that China's transformation of economic development is facing triple "pressure." Firstly, the transformation of the "narrow-style" economic growth pattern originally proposed has not yet been completed, but the conversion of the new "Chinese-style" economic development mode and the broader "wide-style" pattern of overall development has been proposed. Secondly, the problems of underdevelopment (such as tens of millions of poor people, etc.) have not yet been solved. The problems of advanced stage (such as aging) appear. Thirdly, the special problems that China faces (such as population problems, dual economic structure problems and widening income distribution gap) have not yet been solved and the common problems faced by humankind (such as environmental sustainability, human rights protection, the Human Development Index, etc.) come. Wang Jun (2009) argues that there is a problem that China's economic development depends heavily on investment in the macro-power sector and resulting lack of final consumer demand. There is a problem of over-reliance on the secondary industry and the tertiary industry is undeveloped in terms of the momentum of the middle-power sector. There is a problem of being highly dependent on investment in terms of micro-motivation. At the same time, the expansion of government administration expenses has also severely restricted the transformation of the economic development pattern. Shen Guangsi (2009) pointed out that from the reform and opening up to the present, China's economy has achieved sustained and rapid economic growth. However, this economic growth relies mainly on the traditional extensive economic growth pattern. The current main characters of the development pattern are as follows. Economic growth is highly dependent on investment and exports and the role of consumption in stimulating economic growth is weakened. The industrial structure is contradictory. Economic growth is highly dependent on the high input of low-cost resources and production factors. The contribution of scientific and technological progress and innovation to economic growth is low. The restriction of ideology and concepts, the impact of the stage of economic development and the pattern of economic system, the obstacle of the system of economic management and so on are the four factors restricting the transformation of the economic development pattern. Pu Xiaohua and Zhao Shouguo (2010) analyzed the dynamic structure of China's economic development in recent years and concluded that the serious imbalance among investment demand, consumer demand and export demand has become a major problem that restricts the sound and rapid development of our economy.

In addition to analyze the problems and difficulties in transforming the economic development pattern our country from the national level, some scholars also discussed the obstacles to tra

nsforming the development pattern in the developed and underdeveloped regions from the regional level. Taking the Dongguan City, Guangdong Province in the East Coast Region as an example, Li Qiuyang (2010) illustrated that there are five pitfalls in industrial transformation and 
upgrading, including slow labor-intensive industrial upgrading, slow technological upgrading, difficult technical absorption and digestion, difficult adjustment of leading industries and pillar industries, slow development of the tertiary industry and difficulty of industrial gradient transfer, which are the main reasons for the slow transformation of economic development pattern. Liu Peiming (2008) argues that the transformation of the economic development pattern is not only a requirement for the developed areas but also a basic requirement for the less developed regions. However, in the underdeveloped areas, the major contradictions facing the economic development are different from those in developed areas, and the focus of the transformation of economic development pattern is also different. The main task of the transformation of economic development pattern in less developed regions, taking Heyuan City, Guangdong Province for example, is to accelerate economic development, with a focus on the transformation of development power. The difficulty is the irrational structure of government functions caused by the performance competition. Zhu Hong (2010) believes that the difficulties in transforming the economic development pattern in Yunnan are mainly the seven major contradictions, including), namely the contradiction between the scientific development and the catching-up development strategy, the contradiction between the optimization and upgrading of industrial structure and the resource-dependent path, the contradiction between the driving force of investment and the weak demand driven by domestic demand and export, the contradiction between the need of enhancing the endogenous capacity of the economy and the independent innovation, the contradiction between the weak capability, the contradiction between sustainable development and resources and environment, the contradiction between the market-oriented allocation of elements and the transformation of institutional mechanisms, the contradiction between balanced development and the large disparity between urban and rural areas.

\section{Experiences of Transformation of Economic Development Pattern}

The research on the experience of transforming economic development pattern has mainly focused on the experience of the United States, Germany, Japan and the newly industrialized countries and regions in Asia. Yan Kun and Yu Shuyi (2008) did research on various aspects that affected the transformation of the economic development pattern in the United States, Germany, Japan and the newly industrialized countries and regions in Asia and summarized some common experiences that the market economy countries have successfully transformed their economic development pattern, including four aspects. Firstly, the technological progress is the core and fundamental driving force for the transformation of economic growth pattern, as well as the decisive factor in the transformation of the economic development pattern. Secondly, The active role played by the government in public welfare, social distribution, infrastructure, technological progress and foreign trade is an important guarantee for the transformation of the economic development pattern. Thirdly, the development of multi-level education and vocational training provides strong intellectual support for the transformation of the mode of economic development. Fourthly, Efficient and balanced industrial structure is the carrier of the transformation of economic development pattern. Gao Feng (2008) also summarized the experiences of the United States, Germany, Japan and the newly industrialized countries and regions in Asia. The experience gained is that it is necessary to clarify the government's role in the non-competitive field, to strengthen the position of the market mechanism in the competitive field, to play a leading role in promoting emerging industries through scientific and technological innovation, and implementing control measures that are in keeping with the characteristics of national conditions and economic development. Li Haiming (2010) summarized the successful experiences of the transformation of the economic development patterns in the United States, Germany, South Korea and Singapore. He believes that the reason why the United States has changed its economic development pattern is that in addition to expanding investment in fixed assets, attaching importance to the optimization and upgrading of industrial structure and strengthening the government's macro adjustment and control, the United States attaches great importance to the promotion of scientific and technological innovation on the transformation of the economic development pattern. Germany attaches great importance to giving 
full play to its role in transforming the mode of economic development. South Korea focused on timely adjustment of its industrial structure in transforming the economic development pattern. Singapore, on the other hand, paid great attention to human resources development and education. These measures have become important reasons for the successful transformation of the economic development mode.

In addition to summarizing the experience of the developed countries and regions in transforming their economic development patterns, some scholars have also focused their efforts on combing the ideas and practices of success of domestic and foreign cities in transforming their economic development patterns. Li Han (2009) summarized the remarkable achievements made by Erdos, Inner Mongolia in western China in transforming the economic development pattern in an efficient manner in recent years and explained the "Erdos Mode". In his opinion, there are six reasons for Erdos City's success. Firstly, It is necessary to have a strong and wise leadership and to regulate the implementation of scientific decision-making. Secondly, the decision-making of resources should shift to the determination of ability. Thirdly, the economic and social development started relatively late, but should have a high starting point. Fourthly, the leading industries can not be too much, but must be strong. Fifthly, we should focus on the core business of the efficient allocation of major economic resources, and enterprises should focus on making the brand more famous and strong. Sixthly, the agriculture and animal husbandry should pay attention to the ecology, using the industrial chain to promote and form a benign mechanism of ecological and economic development. If conditions permit, the agricultural economy can shift into ecological economy. Gao Ruxi (2010) examines the process of economic transformation in international metropolises such as Tokyo and New York City. He thinks that the core issue of the transformation of metropolitan economic development pattern is the grasp of changes in the contents of urban agglomeration and changes in spatial organization. There are four main conclusions as follows. Firstly, from the point of view of industrial structure, the second and third industries jointly promote the rapid growth of the transition to metropolitan and knowledge-intensive industries, especially the intersection of metropolitan and knowledge-intensive industries. Secondly, from the perspective of industrial layout, in the conversion process, the urban economy still shows obvious characteristics of the stratosphere, and the characteristics of agglomeration in the downtown area become more and more obvious. From the perspective of industrial organization, small and medium-sized enterprises have become the mainstay of the industry, and form an urban cluster of innovative clusters through close competition and cooperation. Fourthly, from the perspective of resource utilization, it emphasized the intensive, refined and sustainable land use.

\section{The Evaluation System of the Transformation of Economic Development Pattern}

In order to quantitatively evaluate the progress and effectiveness of the transformation of the economic development pattern, scholars have tried to set up an evaluation index system for transforming the economic development pattern in recent years, including two main ways.

The first is single indicator method. It refers to measuring the transformation of economic development pattern by using total factor productivity (TFP) in the theory of economic growth in the West and using this indicator as the standard for dividing the types of economic development patterns. Gao Feng (2008) think that the economic development pattern in which the TFPs contribute less than $30 \%$ of the economic growth rate is extensive, $30-50 \%$ is semi-intensive, $50-70 \%$ is intensive, and $70 \%$ is highly intensive. When the contribution rate of total factor productivity to economic growth rate is between $40 \%$ and $60 \%$, the transformation of economic development pattern is in a crucial transitional period, during which the economic development pattern is facing adjustment, consolidation and improvement.

The second is integrated index method. At present, according to various factors that affect the transformation of the mode of economic development, it is a mainstream method to adopt the comprehensive index method to evaluate the transformation of economic development pattern in China. According to the specific requirements of the scientific concept of development and the new industrialization path and the setting principle of the indicator system, Cui Litao (2008) established 
a comprehensive plan that reflects the quality of economic growth, the optimization of economic structure, the investment in science and technology, the impact of economic growth on the environment, the resource conversion efficiency and the economic efficiency, including seven primary indicators of the implementation of economic growth, 17 indicators of the second-level indicators to evaluate the transformation of economic development pattern. He put forward the criteria and comprehensive evaluation methods for judging the type of economic development. $\mathrm{He}$ carried out a comprehensive evaluation of the economic and social development of Zhejiang from 1990 to 2006 and carried out a horizontal comparison with the national economic and social development. Based on the major connotation of the transformation of the economic development pattern in Shanghai, and the existing statistics system and the needs of development, Shen Luying, et al. (2000) constructed an evaluation index system consisting of 6 major areas, 18 first-level indicators and 48 second-level indicators. On this basis, we further adopted the scoring method of experts to judge the importance of each primary area, the first level and the second level to determine the index weights, and then constructed the "1 +6" evaluation index of Shanghai's transformation of economic development pattern, analyzing the changes in the economic development pattern in Shanghai in the "Tenth Five-Year Plan" and "Eleventh Five-Year Plan" periods. Liu Chunyu and Jian Zewu (2010) constructed the index system of transforming economic development pattern from eight aspects of economic structure, industrial structure, independent innovation, agricultural development mode, ecological civilization construction, social undertaking, livelihood and cultural industry and opening to the outside world. Based on the perspective of transformational dynamics, Li Zhiping and Liu Shikui (2010) established an index system for measuring the economic development pattern of Hubei, including two first-level indicators, eight second-level indicators and sixteen third-level indicators.

\section{Thoughts and Countermeasures of Transforming the Way of Economic Development}

There are different views in academia about how to change the economic development pattern, or what are the policies and specific measures of the economic development pattern.

The first is the concept of changing the development ideas. The biggest challenge in transforming the economic development pattern is the confusion of the development ideas, which inevitably leads to mistakes and deviations in practice and hinders the transformation of the economic development pattern.。 "Ideas determine the way." Liu Peiming (2008) argues that underdeveloped areas should take the transformation of development ideas as a precursor to guide the reform of performance appraisal system and the adjustment of government functions and structures, guide enterprises to transform their mode of economic growth, enhance the capability of independent development, and promote the transformation of economic development pattern.

The second is the concept of talent development. Liu Wei (2010) emphasized that the fundamental task of transforming the economic development pattern lies in giving priority to the development of qualified personnel, which is because the key objective of the transformation of the development pattern is the promotion rather than the expansion of investment or the expansion of scale. And talent is the first element in all kinds of factors. The growth and development of economy mainly rely on the improvement of factor efficiency, of which the most important thing is the improvement of the efficiency of personnel and their contribution.

The third is the concept of institutional reform. Huang Taiyan (2007) pointed out that transformation of the economic development pattern needs a sound and efficient realization mechanism, including strengthening independent innovation, improving the quality and efficiency of economic development, accelerating the optimization and adjustment of economic structure, unswervingly taking the road of new industrialization, adhering to the people-oriented scientific development, extensively adopting energy conservation and emission reduction technologies, vigorously developing the environmental protection industry, forming a benign interaction between economic development and energy and environmental protection, and implementing the strategy of sustainable development. Tang Long (2008) think that the government plays a double-edged sword 
in transforming the economic development pattern. Whether the government can give a positive stimulus to the transformation of the economic development pattern lies in the establishment and perfection of the institutional mechanisms that put in place the various measures conducive to transforming the economic development pattern, including scientifically locating the areas of government economic management and ways of macroeconomic regulation and control; pushing forward the reform of most departments; scientifically designing the performance appraisal indicators of government and government officials; reforming the examination and approval of economic systems; establishing price formation mechanisms reflecting the market supply and demand and the scarcity of resources; and deepening the financial constitution taxation system reform. Chen Xiaobing (2009) argues that the transformation of the economic development pattern should be based on the transformation of the growth pattern. However, many problems in the development pattern belong to the category of externalities of the economy, which can not be measured simply by the efficiency of resource allocation, but needs to be realized in the process of perfecting the political, cultural and social systems. Zhong Qingliu (2010) emphasized that a scientific, democratic, fair and impartial system of performance appraisal is the source of motivation for using performance-oriented regulation of incentive mechanisms to ensure the participation of governments at all levels and stimulate the enthusiasm for transforming the development pattern.

The fourth is the concept of technology independent innovation. Wang Yang (2010) believes that independent innovation is the core driver of accelerating the transformation of the economic development pattern. Xia Dongmin (2010) believes that accelerating independent innovation is an important path to promote the transformation of the economic development pattern in China. Only by adhering to the scientific outlook on development, improving our capability of independent innovation, speeding up the transformation of scientific and technological achievements into real productive forces, accelerating the reform of science and technology and speeding up the construction of ambitious scientific and technological personnel can we promote and speed up our independent innovation so as to effectively promote transformation in the economic development pattern. Zhang Baosheng (2010) argues that the impact of independent innovation on the economic development pattern is mainly reflected in the promotion of the four aspects of input structure, demand structure, industrial structure and environmental protection. He also took Henan Province as an example to test the positive effect of independent innovation on the transformation of economic development pattern.

The fifth is the concept of industrial upgrading. Li Qiuyang (2010) argues that the key to the transformation of the economic development pattern is the transformation and upgrading of the industrial structure. The historical experience of many developed countries and newly industrialized countries in the past has proved that the process of industrialization and modernization of a country is the history of industrial restructuring and upgrading. Only by constantly upgrading and transforming the industrial structure, transforming from a lower level to a higher level can it be possible to promote the transformation of the economic development pattern and maintain the sustained economic development and modernization.

The sixth is the concept of expanding consumer demand. Ding Qing (2009) believes that expanding consumer demand is an important means of transforming the economic development pattern. At present, China is at a critical period of accelerating the transformation of the mode of economic development. It is an inevitable choice for China's economic and social development to spare no effort to expand domestic demand and increase the spending power of the people. We should speed up the formulation of relevant mechanisms and policies, increase social security investment and related subsidy policies, improve the consumption environment as soon as possible in the aspects of market guidance and ensure the continuous expansion of rational consumption.

The seventh is the concept of comprehensive and coordinated promotion. Fang Fuqian (2007) pointed out that in the near term, accelerating the transformation of the economic development pattern should mainly focus on the following aspects. First, implementing the people-oriented scientific concept of development; second, reforming the cadre examination system; third, 
developing and improving the socialist market economic system; and fourthly, vigorously developing education and science and technology. Li Yang (2009) argues that the use of both administrative and market can promote conservation-oriented city construction, seizing the strategic opportunities for regional economic development. Accelerating the adjustment of the internal structure of manufacturing industry and firmly grasping the historic opportunity for the development of modern service industry are the breakthrough for promoting the transformation of Shanghai's economic development pattern. Shen Guangsi (2009) holds that it is possible to promote the transformation of the mode of economic development by changing the ideology and concepts, advocating the scientific concept of development, accelerating the optimization of industrial structure and system innovation. Zhang Yunping (2009) put forward the theoretical path and practical countermeasures for the transformation of economic development pattern. Among them, the theoretical path includes sticking to the path of a new type of industrialization with Chinese characteristics; insisting on expanding domestic demand, especially consumer demand; promoting economic growth through the construction of a modern industrial structure; and relying on scientific and technological progress, improving the quality of workers and managing innovation to promote economic growth. The practical countermeasures include promoting the reform of the pricing system of resources and elements and perfecting the incentive mechanism for the efficient use of resources and elements; comprehensively applying financial means such as taxation to guide the market players to change their development pattern consciously; improving the government performance appraisal system and perfecting the supervision system; vigorously developing education and science and technology; vigorously promoting energy conservation and emission reduction and environmental protection; and advocating healthy and civilized consumption patterns. State Council Development Research Center task force (2010) put forward four key strategies to speed up the transformation of the economic development pattern, including the strategy of improving the livelihood of the people and expanding domestic demand with a focus on improving social security and expanding basic public services; the urbanization strategy focusing on migrant workers' citizenization; the industrial transformation and upgrading strategy focusing on enhancing the competitiveness of middle and high industries; the green development strategy with a focus on promoting energy conservation and emission reduction and ecological environment protection, reducing carbon intensity per unit of GDP. Pu Xiaoye and Zhao Shouguo (2010) emphasized that the adjustment of the dynamical structure of economic development and the coordination of the various dynamic structures of consumption, investment and export are the keys to the transformation of the mode of economic development. Zhu Hong pointed out that the focus of accelerating the transformation of economic development in Yunnan Province includes breaking down barriers of ideological concepts; relying on the efficient development and utilization of resources; relying on the optimization and upgrading of industrial structure; and relying on scientific and technological progress to improve the quality of workers and manage innovation.

\section{References}

[1] T. Y. Huang. The Connotation and Realization Mechanism of the Transformation of Economic Development Pattern. Qiu Shi, 2007, (18), pp.6-8.

[2] S. J. Liu. Deepening the Theoretical Understanding of the Transformation of the Development Pattern. Academic Exchange, 2007, (11), pp.1-6.

[3] X. R. Liu. Transforming Economic Development Pattern Should Stick to Three Orientations. Journal of Social Science of Hunan Normal University, 2009, (5) pp. 25-27.

[4] Y. P. Zhang. Theoretical Exploration and Practical Countermeasure in Transforming the Mode of Economic Development. Shandong Social Science, 2009, (11), pp.119-121.

[5] Qi Jianguo. To guide the transformation of the mode of economic development and the use of Scientific Outlook on Development [J]., 2010 (04): 5-12+136.

[6] Shen Luying, Ge Yin, Yin Wenjie, Huang Yue Zhan, Shanghai Xinye. Change the mode of economic development evaluation index system of the development of [J]. science, 2010 (06): 11-35. 
[7] Zhu Zheng. With Scientific Outlook on Development to promote the transformation of economic development mode -- Based on China's economic development mode change 30 years of [J]. in modern economy, 2009 (01): 26-30.

[8] Wang. Improve the transformation of economic development mode of the dynamic problems of [J]. theory research journal, 2009 (09): 54-59+127.

[9] Shen Guangsi. Restricting factors and Countermeasures of [J]. statistics and decision of transformation of economic development in China, 2009 (22): 106-108.

[10]Po ye, Zhao Shouguo. [J]. economic problems in dynamic analysis of structural changes in China's economic development mode, 2010 (04): 39-45.

[11]Li Qiuyang. Try to solve the problem of changing the way of economic development -- Taking Dongguan city of Guangdong as an example of [J]. academic forum, 2010,33 (04): 117-122.

[12]Liu Peiming. The key and path of the transformation of economic development in underdeveloped areas: taking Heyuan as an example, [J]. Journal of Guangdong radio and Television University, 2008 (03): 52-55.

[13]Zhu Hong. Research on the difficulties and key problems of Yunnan's transformation of economic development mode [J]. Journal of the Yunnan Institute of administration, 2010,12 (01): 172-174.

[14] Yan Kun, tree 1. Analysis of factors affecting the transformation of economic development mode: national practice and experience [J]. foreign tax, 2008 (03): 8-12.

[15] Gao Feng. Foreign transformation of economic development mode institutional mechanism for reference to the [J]. world economic and political forum, 2008 (03): 113-116.

[16] Li Haiming. Research on the evolution of the thought of economic development by the Party Central Committee [D]. Changchun University of Science and Technology, 2010.

[17]Li Hanlin. A successful example of the mode of economic development in Western Chinese transition -- Inner Mongolia "Erdos model" interpretation of [J]. Gansu theory, 2009 (02): 112-119.

[18] Gao Ruxi. International comparison and experience of changing the mode of economic development (under [J].) the development of science, 2009 (04): 85-92.

[19]Cui Litao. Study on the transformation of Zhejiang's economic development mode [D]. Zhejiang Gongshang University, 2008.

[20]Liu Chunyu, Yan Zewu. [J]. index system of macro economic management and construction of the transformation of economic development mode, 2010 (06): 40-41.

[21]Li Zhiping, Liu Shikui. Dynamic measurement of the transformation of economic development mode and empirical [J]. statistics and decision-making, 2010 (11): 101-103.

[22]Liu Wei. The fundamental change in the way of economic development lies in the talent development of [J]. Chinese talents, 2010 (11): 20-21.

[23] Tang long. The key to changing the way of economic development lies in the reform of the government's reform of the [J]. economic system, 2008 (06): 135-138.

[24]Chen Xiaobing. [J]. theory study of activation on the change of system innovation and the mode of economic development, 2009 (08): 47-51.

[25]Zhong Qingliu[J]. theory analysis guide the dynamic mechanism to promote the transformation of economic development mode, 2010 (04): 24+28.

[26] Wang Yang. Independent innovation is the core driving force for speeding up the transformation of economic development mode [J]. academic research, 2010 (03): 1-5.

[27]Xia Dongmin. Independent innovation and transformation of the mode of economic development [J]. Mao Zedong Deng Xiaoping theory research, 2010 (03): 21-25+85.

[28]Zhang Baosheng. Empirical analysis of independent innovation to promote the transformation of the mode of economic development -- a case study of Henan province [J]. Chinese science and Technology Forum, 2010 (03): 31-37.

[29]Dengqen. Expanding consumer demand: an important means of [J]. flag presentation change the mode of economic development, 2009 (23): 14-16. 
[30]Fang Fuqian. On the three problems of transforming the way of economic development [J]. economic theory and economic management, 2007 (11): 12-16.

[31]Li Yang. The direction and breakthrough of Shanghai's transformation of the mode of economic development and the scientific development of [J]., 2009 (05): 3-21. 